\title{
Waste-to-Energy: Production of Fuel Gases from Plastic Wastes
}

\author{
Cheuk-Fai Chow ${ }^{1, *(\mathbb{D}}$, Chow-Shing Lam ${ }^{2}$, Kai-Chung Lau ${ }^{2}$ and Cheng-Bin Gong ${ }^{3}$ \\ 1 Department of Science and Environmental Studies, The Education University of Hong Kong, \\ 10 Lo Ping Road, Tai Po, Hong Kong, China \\ 2 Department of Chemistry, City University of Hong Kong, Kowloon Tong, Hong Kong, China; \\ chowslam@cityu.edu.hk (C.-S.L.); kaichung@cityu.edu.hk (K.-C.L.) \\ 3 The Key Laboratory of Applied Chemistry of Chongqing Municipality, \\ College of Chemistry and Chemical Engineering, Southwest University, Chongqing 400715, China; \\ gongcbtq@swu.edu.cn \\ * Correspondence: cfchow@eduhk.hk; Tel.: +852-29487671
}

Citation: Chow, C.-F.; Lam, C.-S.

Lau, K.-C.; Gong, C.-B.

Waste-to-Energy: Production of Fuel Gases from Plastic Wastes. Polymers 2021, 13, 3672. https://doi.org/ $10.3390 /$ polym 13213672

Academic Editor: Carola Esposito Corcione

Received: 6 September 2021

Accepted: 20 October 2021

Published: 25 October 2021

Publisher's Note: MDPI stays neutra with regard to jurisdictional claims in published maps and institutional affiliations.

Copyright: (c) 2021 by the authors. Licensee MDPI, Basel, Switzerland. This article is an open access article distributed under the terms and conditions of the Creative Commons Attribution (CC BY) license (https:// creativecommons.org/licenses/by/ $4.0 /)$.

\begin{abstract}
A new mechanochemical method was developed to convert polymer wastes, polyethylene (PE), polypropylene (PP), and polyvinyl chloride (PVC), to fuel gases $\left(\mathrm{H}_{2}, \mathrm{CH}_{4}\right.$, and $\mathrm{CO}$ ) under ball-milling with $\mathrm{KMnO}_{4}$ at room temperature. By using various solid-state characterizations (XPS, SEM, EDS, FTIR, and NMR), and density functional theory calculations, it was found that the activation followed the hydrogen atom transfer (HAT) mechanism. Two metal oxidant molecules were found to abstract two separate hydrogen atoms from the $\alpha-\mathrm{CH}$ and $\beta-\mathrm{CH}$ units of substrates, $\left[-{ }_{\beta} \mathrm{CH}_{2}-\alpha \mathrm{CH}(\mathrm{R})-\right]_{n}$, where $\mathrm{R}=\mathrm{H}$ in $\mathrm{PE}, \mathrm{R}={ }_{\gamma} \mathrm{CH}_{3}$ in $\mathrm{PP}$, and $\mathrm{R}=\mathrm{Cl}$ in $\mathrm{PVC}$, resulting in a di-radical, $\left[-{ }_{\beta} \mathrm{CH}^{\bullet}-{ }_{\alpha} \mathrm{C}^{\bullet}(\mathrm{R})-\right]$. Subsequently, the two unpaired electrons of the di-radical were recombined into an alkene intermediate, $\left[-{ }_{\beta} \mathrm{CH}={ }_{\alpha} \mathrm{C}(\mathrm{R})-\right]$, which underwent further oxidation to produce $\mathrm{H}_{2}, \mathrm{CH}_{4}$, and $\mathrm{CO}$ gases.
\end{abstract}

Keywords: ball-milling; polymer degradation; $\mathrm{C}-\mathrm{H}$ bond activation; hydrogen atom transfer

\section{Introduction}

The great demand for plastics in modern society and the huge amounts of unrecycled plastic waste produced worldwide pollute our environment. In 2019, the amount of plastic wastes produced worldwide every year reached 368 million metric tons [1]. Eight billion polyethylene (PE) shopping bags are disposed of in landfill each year [1]. The handling of these several hundred million tons of "extra-long-lasting" wastes annually is currently an unsolved problem because we still do not have economical, high-efficiency technologies for plastic waste management. The understanding of the activation of these inert polymers could lead to utilization of these hydrocarbon resources, making use of the enormous amounts of hydrocarbon wastes. Unfortunately, the current recycling efficiency of these materials is not as good as required. For example, in 2018, approximately 75.5\% of plastic materials (27.0 million tons) were sent to landfill in the USA [2], while in the EU, approximately $14.9 \%$ of plastic wastes (7.2 million tons) were sent to landfill [1]. Although alternative strategies for the conversion of unrecycled plastic wastes into fuel or useful materials are in continuous development, including photolysis [3], pyrolysis [4], ultrasound [5], biodegradation [6], chemolysis [7], ozonolysis [8], and catalytic degradation [9], they involve non-selective oxidation and are prone to creating secondary pollution, such as the emission of polycyclic aromatic hydrocarbons and/or dioxin. Given these factors, developing new methods to convert plastic into useful chemical resources, such as fuel gases, organic fuels and/or fine chemicals, in a rapid, mild, and cost-effective way, is important.

Mechanochemical degradation of polymers was first investigated approximately 50 years ago [10]. According to the IUPAC Compendium of Chemical Terminology, a mechanochemical reaction is defined as a "chemical reaction that is induced by the direct 
absorption of mechanical energy" [11]. Mechanical energy, such as that arising from friction, impacts, and collisions, can offer certain advantages [12,13], as such processes are simple, solvent-free, and effective for various chemical reactions and processes including the formation of carbon-carbon [14] and carbon-heteroatom bonds [15], redox reactions by solid oxidants [16] and reductants [17], and cross dehydrogenative coupling reactions [18]. In addition, mechanochemistry is gaining attention as it has been demonstrated to be applicable in various important scientific areas, such as catalysts [19], nanoparticles [20], organic synthesis [21], MOFs [22], oxides [23], biomaterials [24], supramolecular chemistry [25], and process engineering [26]. In recent years, some attempts have been made to apply this technology to plastic waste management [27] because plastic wastes can be broken down under mechanical force such as agitation, grinding, or extrusion [28-36]. Polyvinyl chloride (PVC) was reported to be partially degraded, showing a decrease in molecular weight, formation of $\mathrm{C}=\mathrm{C}$ bonds in its structure, and production of chlorine ion, when subjected to a mechanochemical process in the presence of metal hydroxides or metal oxides [31,32]. In another study, after undergoing a mechanochemical process by ball-milling with $\mathrm{CaO}$ and $\mathrm{Ni}(\mathrm{OH})_{2}$ followed by pyrolysis, $\mathrm{PVC}$ was able to generate hydrogen, carbon monoxide, carbon dioxide, and methane gas as fuels. This waste-to-energy mechanochemical process targeting PVC wastes is very attractive, but it requires high temperatures $\left(450^{\circ} \mathrm{C}\right)$ and is a multi-step process [35].

Thus, we herein report the $\mathrm{C}-\mathrm{H}$ activation of solid PE, polypropylene (PP), and PVC to yield fuel gases including hydrogen, methane, and carbon monoxide by using a high-valent manganese oxidant $\left(\mathrm{KMnO}_{4}\right)$ under ball-milling [36] mechanochemical reaction conditions. We found that the first step of the interaction between $\mathrm{KMnO}_{4}$ and the $\alpha-\mathrm{CH}$ unit of the polymers, i.e., $\left[-{ }_{\beta} \mathrm{CH}_{2}-\alpha \mathrm{CH}(\mathrm{R})-\right]_{n}$, where $\mathrm{R}=\mathrm{H}$ in $\mathrm{PE}, \mathrm{R}={ }_{\gamma} \mathrm{CH}_{3}$ in $\mathrm{PP}$, and $\mathrm{R}=\mathrm{Cl}$ in PVC, results in the homolytic cleavage of the $\alpha-\mathrm{CH}$ unit via hydrogen atom transfer (HAT). Through density functional theory (DFT) calculations, we found that the intermediate generated after the first step, $\left[\left(\mathrm{KMn}^{\mathrm{VI}} \mathrm{O}_{3}(\mathrm{OH})\left(-{ }_{\beta} \mathrm{CH}_{2}-\alpha \mathrm{C}^{\bullet}(\mathrm{R})-\right)\right]\right.$, dissociates into a free radical, [ $\left.{ }_{\beta} \mathrm{CH}_{2}-{ }_{\alpha} \mathrm{C}^{\bullet}(\mathrm{R})-\right]$, leading to a second HAT between a new molecule of $\mathrm{KMnO}_{4}$ and the ${ }_{\beta}-\mathrm{CH}_{2}$ unit to form a di-radical, $\left[{ }_{\beta} \mathrm{C}^{\bullet} \mathrm{H}-{ }_{\alpha} \mathrm{C}^{\bullet}(\mathrm{R})-\right]$. Subsequently, the two unpaired electrons of the di-radical are recombined into an alkene entity $\left[{ }_{\beta} \mathrm{CH}={ }_{\alpha} \mathrm{C}(\mathrm{R})-\right]$. In the presence of sufficient $\mathrm{KMnO}_{4}$, more alkane radicals were formed; hence hydrogen, methane, and carbon monoxide were eventually produced. This protocol was subsequently applied in the conversion of real plastic waste samples, including HDPE bottles, PP microwave containers, and PVC water pipes into fuel gases. These findings differ significantly from the previously reported chemolysis of PVC with $\mathrm{KMnO}_{4}$ conducted in the liquid phase, as chemolysis results in only the partial dechlorination of PVC [37]. We also note that, recently, one study demonstrated the solvent-free oxidative dehydrogenation of a semiconjugated substrate, $\gamma$-terpinene, to a fully conjugated product, $p$-cymene, using $\mathrm{KMnO}_{4}$ via ball-milling [16].

\section{Materials and Methods}

\subsection{Materials and General Procedure}

PE (average $M_{\mathrm{w}} \approx 35,000$ and average $M_{\mathrm{n}} \approx 7700$ ), PP (average $M_{\mathrm{w}} \approx 12,000$ and average $M_{\mathrm{n}} \approx 5000$ ), $\mathrm{PVC}$ (average $M_{\mathrm{W}} \approx 43,000$ and average $M_{\mathrm{n}} \approx 22,000$ ), $\mathrm{KMnO}_{4}$, $\mathrm{KHSO}_{4}$, and $\mathrm{Al}_{2}\left(\mathrm{SO}_{4}\right)_{3}$ were purchased from Sigma-Aldrich (HKSAR). The ball-milling process was performed at $25^{\circ} \mathrm{C}$ in a vertical planetary ball mill (DECO-PBM-V-0.4L) using different sizes of hardened steel balls with diameters of 3, 5, and $10 \mathrm{~mm}$ and a sealed airtight stainless-steel chamber of $108 \mathrm{~cm}^{3}$ in volume.

Infrared spectra in the range of $500-4000 \mathrm{~cm}^{-1}$ were recorded on a Perkin Elmer Frontier FTIR spectrometer. An Agilent 7890B gas chromatograph coupled with a thermal conductivity detector (TCD) was used to perform the gas analyses. Injections were conducted manually with a sample injection volume of $100 \mu \mathrm{L} . \mathrm{Cl}_{2}$ and $\mathrm{CO}_{2}$ gases were quantified with a capillary column (Agilent HP-PLOT Q column $(40 \mu \mathrm{m}, 30 \mathrm{~m} \times 0.53 \mathrm{~mm}$ i.d.)) Injections were carried out in splitless mode. Argon was used as the carrier gas at a flow 
rate of $5.0 \mathrm{~mL} / \mathrm{min}$. The temperature was set at $40^{\circ} \mathrm{C}$ for $5 \mathrm{~min}$, the injection temperature was $100^{\circ} \mathrm{C}$, and the detector temperature was $250^{\circ} \mathrm{C} . \mathrm{H}_{2}, \mathrm{CH}_{4}$, and $\mathrm{CO}$ gases were quantified using an Agilent J\&W CP-Molsieve 5- $\AA$ capillary column $(10 \mu \mathrm{m}, 30 \mathrm{~m} \times 0.32 \mathrm{~mm}$ i.d. $)$. Injections were set as a 4:1 split at $12 \mathrm{~mL} / \mathrm{min}$. Argon was used as the carrier gas at a flow rate of $18.0 \mathrm{~mL} / \mathrm{min}$. The temperature was set at $60^{\circ} \mathrm{C}$ for $6 \mathrm{~min}$, the injection temperature was $80^{\circ} \mathrm{C}$, and the detector temperature was $150^{\circ} \mathrm{C}$. SEM (JEOL-6390) coupled with EDS was used to study the surface morphologies of the oxidized polymer particles. XPS (Kratos Axis Ultra DLD) was used to study the functional groups at the surface of the oxidized polymer particles. All solid-state ${ }^{13} \mathrm{C}-\mathrm{NMR}$ measurements were performed on a JEOL ECZ500R $500 \mathrm{MHz}$ solid-state NMR spectrometer at a $20 \mathrm{MHz}$ proton resonance frequency, using a typical $\pi / 2$ pulse length of $\sim 3.2 \mu$ s and a receiver dead time of $\sim 13 \mu$ s at $25^{\circ} \mathrm{C}$.

\subsection{Ball-Milling of PE, PP, and PVC Using $\mathrm{KMnO}_{4}$}

Virgin PE, PP, and PVC powders were crushed to obtain particle sizes in the range of 65-125 $\mu \mathrm{m}$ before use. In a typical experiment, oxidation of the polymer, i.e., PE ( $0.50 \mathrm{~g}$, $18 \mathrm{mmol})$, PP $(0.50 \mathrm{~g}, 12 \mathrm{mmol})$, or PVC $(0.50 \mathrm{~g}, 8 \mathrm{mmol})$, was performed by adding $\mathrm{KMnO}_{4}$ (1.2 molar equivalents: $21.6 \mathrm{mmol}$ for PE; $14.4 \mathrm{mmol}$ for PP; and $9.6 \mathrm{mmol}$ for PVC) with or without $\mathrm{KHSO}_{4}$ to an airtight stainless-steel chamber $\left(108 \mathrm{~cm}^{3}\right)$ with a mix of stainlesssteel balls (diameters of 3,5, and $10 \mathrm{~mm}$ ); the ball-to-powder ratio was 55:1. The reaction was conducted under vacuum at $25{ }^{\circ} \mathrm{C}$. The chamber was evacuated, sealed, and fixed in a planetary ball-milling machine. The ball-milling reaction was conducted at a speed of $800 \mathrm{rpm}$ for $12-48 \mathrm{~h}$. The gases produced were collected and analyzed by GC-TCD using the abovementioned procedure.

The black solid residues were washed three times with deionized water. The total organic/inorganic carbon content of the dissolved aqueous solution was determined using a Shimadzu TOC-L CSH high-sensitivity total organic analyzer. The total chloride content of the dissolved solution was performed by standard titration methods using $\mathrm{AgNO}_{3}$ and $\mathrm{KCrO}_{4}$ as an indicator.

The solid residues left after washing were manganese oxide and insoluble organic polymers. The oxidation state of manganese was studied by the iodometric titrations. After the insoluble organic polymers were obtained by washing the crude solids in aqua regia to eliminate manganese oxide particles, they were oven-dried at $100^{\circ} \mathrm{C}$. The collected organic solids (denoted PE [ox $]_{\text {vac }}, \mathbf{P P}[\mathbf{o x}]_{\mathbf{v a c}}$, and PVC[ox $]_{\text {vac }}$ ) were analyzed by FTIR spectroscopy, solid-state ${ }^{13} \mathrm{C}-\mathrm{NMR}, \mathrm{SEM}$, and XPS.

\subsection{DFT Calculations}

DFT calculations were performed using the B3LYP [38-40] functional and the LanL2DZ basis set [41] for Mn and the 6-311++G(d,p) basis set for non-metal atoms. The optimization and frequency calculations were performed in the gas phase. No solvent effects were considered. For these calculations, octane, 2,4,6-trimethyloctane, and 3,5-dichlorooctane were used to represent PE, PP, and PVC, respectively. The geometries were fully optimized, and the structures were confirmed as true minima based on frequency calculations. None of the reactants, intermediates, or products had imaginary frequencies, whereas the TSs had a single imaginary frequency. The connectivity of the TS structures was confirmed by intrinsic reaction coordinate calculations.

\section{Results and Discussion}

\subsection{Oxidation of Plastic Wastes by Solid-State Ball-Milling}

In a typical experiment, the solid-state ball milling of polyolefins (PE, PP, and PVC $(0.50 \mathrm{~g})$ ) with $\mathrm{KMnO}_{4}$ (1.2 molar equivalents: $21.6 \mathrm{mmol}$ for PE; $14.4 \mathrm{mmol}$ for PP; and $9.6 \mathrm{mmol}$ for PVC) at a speed of $800 \mathrm{rpm}$ under vacuum for $48 \mathrm{~h}$ resulted in a complete decomposition of the polymers. It led to the production of major coal gas components, including gaseous $\mathrm{CO}, \mathrm{H}_{2}$, and $\mathrm{CH}_{4}$. Figure $\mathrm{S} 1$ shows the gas chromatography with thermal conductivity detection (GC-TCD) spectra of the gases collected from the reactions. 
Moderate amounts of $\mathrm{H}_{2}(3.5-5.6 \mathrm{mmol})$ and $\mathrm{CO}(4.6-13.3 \mathrm{mmol})$ gases were generated, which had retention times of 1.30 and $3.63 \mathrm{~min}$, respectively. A significant amount of methane (1.8 and $4.2 \mathrm{mmol}$ ) was also detected with a retention time of $2.41 \mathrm{~min}$ in the degradation of PE and PP, whereas only a small amount of methane $(0.6 \mathrm{mmol})$ was produced from the degradation of PVC. The complete dechlorination of PVC was achieved during the ball milling reaction, and a quantitative amount of chloride anions $(8.0 \mathrm{mmol})$ was produced during the process. A large amount of carbon in the polymers was degraded in the form of $\mathrm{CO}_{3}{ }^{2-}(6.8-14.5 \mathrm{mmol})$, and neither $\mathrm{CO}_{2}$ nor $\mathrm{Cl}_{2}$ gas was detected by GC. Table 1 shows the product yields from the oxidation of the polymer samples. Through iodometric titrations, the manganese residue was determined to be manganese (II) oxide, which could potentially be recycled to $\mathrm{KMnO}_{4}$ by chemical/electrochemical oxidation [42]. Various oxidants, including $\mathrm{Mn}$ (acetate), $\mathrm{Mn}_{2} \mathrm{O}_{3}, \mathrm{MnO}_{2}, \mathrm{~K}_{2} \mathrm{MnO}_{4}, \mathrm{~K}_{2} \mathrm{Cr}_{2} \mathrm{O}_{7}$, oxone, $\mathrm{PbO}_{2}$, and $\mathrm{K}_{2} \mathrm{~S}_{2} \mathrm{O}_{8}$, were also used to degrade PE, PP, and PVC; however, aside from potassium permanganate, the tested oxidants were ineffective in oxidizing/activating the polymers. Interestingly, Tang and coworkers reported the formation of $\mathrm{H}_{2}, \mathrm{CH}_{4}$, and $\mathrm{CO}$ through the catalytic pyrolysis of PP by the formation of alkane radicals with heat $\left(600^{\circ} \mathrm{C}\right)$ [43]. Therefore, we initially postulated that the energy released from the polymer degradation, especially in the presence of excess $\mathrm{KMnO}_{4}$, could dissociate the polymer into these gases. GC-MS was therefore used to analyze the abovementioned degradation process. Various alkene-based intermediates possessing carbon numbers ranging from 8 to 18 (such as 2,6-dimethyl-3-heptene, 2,2-dimethyl-3-octene, and 4,6,8-trimethyl-1-nonene) and aromatic hydrocarbons with 6-14 carbon atoms (such as benzene, xylene, and phenanthrene) were identified in the extractant of the polymer degradation products. These results confirm that the degradation proceeds via a radical mechanism through which random aromatic and aliphatic hydrocarbons can be formed (Scheme 1) [43,44].

Table 1. Characteristics of the products recovered from the mechanochemical degradation of PE (0.50 g, $18 \mathrm{mmol})$, PP (0.50 g, $12 \mathrm{mmol})$, or PVC (0.50 g, $8 \mathrm{mmol})$ with using $\mathrm{KMnO}_{4}$ (1.2 molar equivalents: $21.6 \mathrm{mmol}$ for PE; $14.4 \mathrm{mmol}$ for PP; and $9.6 \mathrm{mmol}$ for PVC) ${ }^{\mathrm{a}}$.

\begin{tabular}{|c|c|c|}
\hline Entry & Substrate & Products (mmol) \\
\hline 1 & Virgin PE & $\begin{array}{c}\mathrm{H}_{2}(5.2 \mathrm{mmol}), \mathrm{CH}_{4}(2.7 \mathrm{mmol}), \mathrm{CO}(6.8 \mathrm{mmol}), \mathrm{CO}_{3}{ }^{2-}(16.2 \mathrm{mmol}) \\
\left(7.5 \%, 18.9 \% \text {, and } 45.0 \% \text { of the carbon atom from polymer feed converted to } \mathrm{CH}_{4}\right. \\
\mathrm{CO} \text {, and } \mathrm{CO}_{3}{ }^{2-} \text {, respectively; } 14.5 \% \text { and } 15.0 \% \text { of the hydrogen atom from polymer } \\
\left.\text { feed converted to } \mathrm{H}_{2} \text { and } \mathrm{CH}_{4} \text {, respectively. }\right)\end{array}$ \\
\hline 2 & Virgin PP & $\begin{array}{c}\mathrm{H}_{2}(5.6 \mathrm{mmol}), \mathrm{CH}_{4}(4.2 \mathrm{mmol}), \mathrm{CO}(5.9 \mathrm{mmol}), \mathrm{CO}_{3}{ }^{2-}(14.5 \mathrm{mmol}) \\
\left(11.7 \%, 16.4 \% \text {, and } 40.3 \% \text { of the carbon atom from polymer feed converted to } \mathrm{CH}_{4}\right. \\
\mathrm{CO} \text {, and } \mathrm{CO}_{3}{ }^{2-} \text {, respectively; } 15.6 \% \text { and } 23.3 \% \text { of the hydrogen atom from polymer } \\
\left.\text { feed converted to } \mathrm{H}_{2} \text { and } \mathrm{CH}_{4} \text {, respectively. }\right)\end{array}$ \\
\hline 3 & Virgin PVC & $\begin{array}{c}\mathrm{H}_{2}(3.5 \mathrm{mmol}), \mathrm{CH}_{4}(0.4 \mathrm{mmol}), \mathrm{CO}(8.9 \mathrm{mmol}), \mathrm{CO}_{3}{ }^{2-}(4.6 \mathrm{mmol}), \mathrm{Cl}^{-}(8.0 \mathrm{mmol}) \\
\left(2.5 \%, 55.6 \% \text {, and } 28.8 \% \text { of the carbon atom from polymer feed converted to } \mathrm{CH}_{4},\right. \\
\mathrm{CO} \text {, and } \mathrm{CO}_{3}{ }^{2-} \text {, respectively; } 29.2 \% \text { and } 6.7 \% \text { of the hydrogen atom from polymer } \\
\text { feed converted to } \mathrm{H}_{2} \text { and } \mathrm{CH}_{4} \text {, respectively; } 100 \% \text { of the chlorine atom from } \\
\left.\text { polymer feed converted to } \mathrm{Cl}^{-} .\right)\end{array}$ \\
\hline 4 & HDPE washing bottles & $\begin{array}{c}\mathrm{H}_{2}(4.0 \mathrm{mmol}), \mathrm{CH}_{4}(2.0 \mathrm{mmol}), \mathrm{CO}(6.1 \mathrm{mmol}), \mathrm{CO}_{3}{ }^{2-}(18.9 \mathrm{mmol}) \\
\left(5.6 \%, 16.9 \% \text {, and } 52.5 \% \text { of the carbon atom from polymer feed converted to } \mathrm{CH}_{4},\right. \\
\mathrm{CO} \text {, and } \mathrm{CO}_{3}{ }^{2-} \text {, respectively; } 11.1 \% \text { and } 11.1 \% \text { of the hydrogen atom from polymer } \\
\left.\text { feed converted to } \mathrm{H}_{2} \text { and } \mathrm{CH}_{4} \text {, respectively. }\right)\end{array}$ \\
\hline 5 & PP microwave boxes & $\begin{array}{c}\mathrm{H}_{2}(5.0 \mathrm{mmol}), \mathrm{CH}_{4}(4.7 \mathrm{mmol}), \mathrm{CO}(5.4 \mathrm{mmol}), \mathrm{CO}_{3}{ }^{2-}(11.6 \mathrm{mmol}) \\
\left(13.1 \%, 15.0 \% \text {, and } 32.2 \% \text { of the carbon atom from polymer feed converted to } \mathrm{CH}_{4},\right. \\
\mathrm{CO} \text {, and } \mathrm{CO}_{3}{ }^{2-} \text {, respectively; } 13.9 \% \text { and } 26.1 \% \text { of the hydrogen atom from polymer } \\
\left.\text { feed converted to } \mathrm{H}_{2} \text { and } \mathrm{CH}_{4} \text {, respectively. }\right)\end{array}$ \\
\hline
\end{tabular}


Table 1. Cont.

\begin{tabular}{|c|c|c|}
\hline Entry & Substrate & Products (mmol) \\
\hline 6 & PVC water piping & $\begin{array}{c}\mathrm{H}_{2}(2.5 \mathrm{mmol}), \mathrm{CH}_{4}(0.4 \mathrm{mmol}), \mathrm{CO}(6.2 \mathrm{mmol}), \mathrm{CO}_{3}{ }^{2-}(6.6 \mathrm{mmol}), \mathrm{Cl}^{-}(8.0 \mathrm{mmol}) \\
\left(2.5 \%, 38.8 \% \text {, and } 41.3 \% \text { of the carbon atom from polymer feed converted to } \mathrm{CH}_{4}\right. \\
\mathrm{CO} \text {, and } \mathrm{CO}_{3}{ }^{2-} \text {, respectively; } 20.8 \% \text { and } 6.7 \% \text { of the hydrogen atom from polymer } \\
\text { feed converted to } \mathrm{H}_{2} \text { and } \mathrm{CH}_{4} \text {, respectively; } 100 \% \text { of the chlorine atom from } \\
\left.\text { polymer feed converted to } \mathrm{Cl}^{-} .\right){ }^{\mathrm{b}}\end{array}$ \\
\hline
\end{tabular}

${ }^{a}$ Reaction conditions: Ball-milling of the polymer in the presence of $\mathrm{KMnO}_{4}$ at $800 \mathrm{rpm}$ for $48 \mathrm{~h}$ under vacuum. ${ }^{\mathrm{b}}$ Percentage conversion $(\%)=($ moles of hydrogen or carbon atom in fuel gas $/$ moles of hydrogen or carbon atom in polymer feed $) \times 100$.

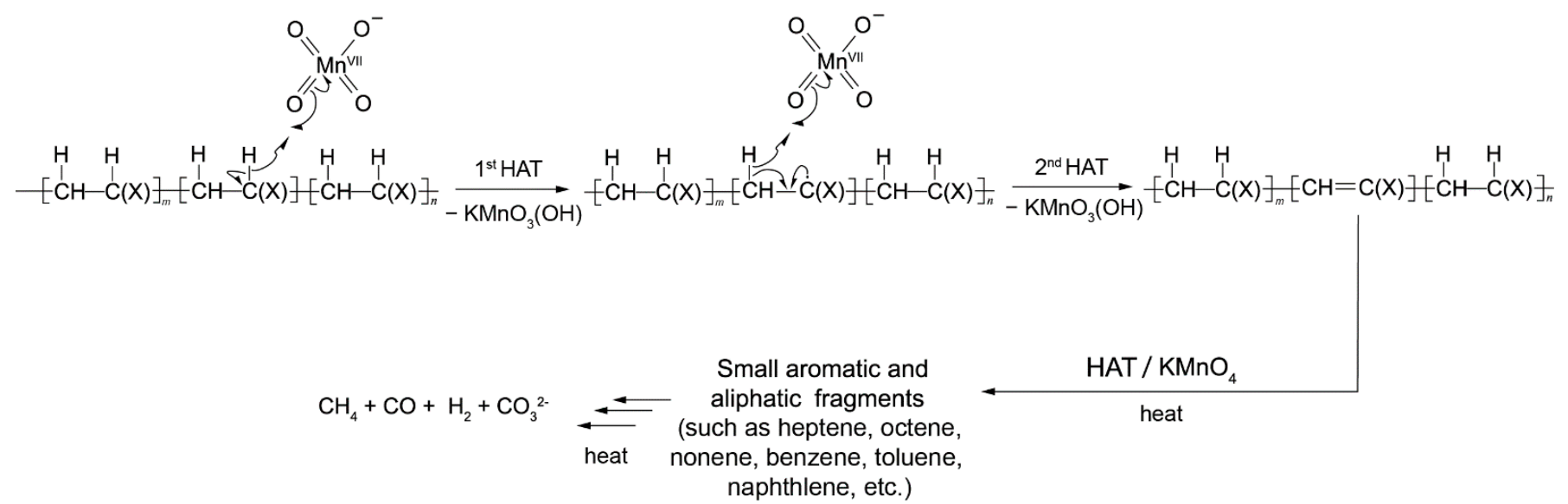

Scheme 1. Double HAT mechanism for desaturation: $\mathrm{C}-\mathrm{H}$ bond activation of PE, PP, and PVC by two molecules of $\mathrm{KMnO}_{4}$ through the ball-milling reaction $\left\{\left[-{ }_{\beta} \mathrm{CH}_{2}{ }_{\alpha} \mathrm{CH}(\mathrm{R})-\right]_{n}\right.$, where $\mathrm{R}=\mathrm{H}$ in $\mathrm{PE}, \mathrm{R}={ }_{\gamma} \mathrm{CH}_{3}$ in $\mathrm{PP}$, and $\mathrm{R}=\mathrm{Cl}$ in $\left.\mathrm{PVC}\right\}$.

HDPE waste bottles, used PP microwave boxes, and PP water pipes were used to test the applicability of the developed protocol to degrade real polymer waste samples. Upon application of the same mechanochemical process to the polymer waste samples, moderate amounts of $\mathrm{CO}(4.1-9.2 \mathrm{mmol}), \mathrm{H}_{2}(2.6-5.0 \mathrm{mmol})$, and $\mathrm{CH}_{4}(0.6-4.7 \mathrm{mmol})$ were generated from the real samples (Table 1). Burning the gases generated from the reaction of the HDPE sample with excess $\mathrm{KMnO}_{4}$ resulted in a high-temperature blue flame (see Video S1 in the Supplementary Information). Comparison of the results obtained for the standard polymers and these samples suggested that the mechanochemical prototype was not affected by the presence of additives (dyes or other plasticizers) or dirt in the polymer samples.

\subsection{Characterization of the Intermediates and Products during Ball-Milling of PE, PP, and PVC} with $\mathrm{KMnO}_{4}$

The mechanism of the abovementioned reaction was comprehensively investigated by various solid-state spectroscopic characterizations (XPS, SEM, EDS, FTIR, and NMR), and density functional theory calculations. In a typical experiment, the solid-state ball milling of polyolefins (PE, PP, and PVC $(0.50 \mathrm{~g}))$ with $\mathrm{KMnO}_{4}(0.2$ molar equivalents: $3.6 \mathrm{mmol}$ for $\mathrm{PE}$; $2.4 \mathrm{mmol}$ for PP; and $1.6 \mathrm{mmol}$ for PVC) and $\mathrm{KHSO}_{4}$ (as an acid, 0.2 molar equivalents: $3.6 \mathrm{mmol}$ for PE; $2.4 \mathrm{mmol}$ for PP; and $1.6 \mathrm{mmol}$ for PVC) at a speed of $800 \mathrm{rpm}$ under vacuum for $48 \mathrm{~h}$ resulted in brownish-black solid inorganic/organic mixtures. The collected solids were washed with deionized water to give a colorless filtrate, which indicated that the $\mathrm{KMnO}_{4}$ had been consumed. The average oxidation states of the manganese residues after the reactions were determined as $3.6 \pm 0.01$ (PE substrate), $3.8 \pm 0.14$ (PP substrate), and $4.0 \pm 0.09$ (PVC substrate), based on iodometric titrations. The appearance of a strong broad infrared (IR) absorbance band at $\sim 560 \mathrm{~cm}^{-1}$ indicates the formation of $\mathrm{Mn}^{\mathrm{IV}} \mathrm{O}_{2}$ during the reactions. The solid mixtures were then washed with aqua regia to eliminate the inorganic oxide and to yield the oxidized forms of PE, PP, and PVC, denoted PE[ox $]_{\text {vac/acid }}$ 
(77.9\% yield), PP[ox $]_{\text {vac/acid }}(85.1 \% \text { yield), and PVC[ox }]_{\text {vac/acid }}(39.7 \%$ yield), respectively. In the absence of acid, the corresponding $\mathbf{P E / P P / P V C}[\mathbf{o x}]_{\text {vac }}$ products were also obtained.

During solid-state ball-milling of solid PE, PP, and $\mathrm{PVC}^{\text {by }} \mathrm{KMnO}_{4}$, the formation of organic intermediates took place. Figure 1a,c shows the FTIR spectra of the virgin PP and PP $[\mathbf{o x}]_{\text {vac/acid }}$. Compared with the spectrum of the virgin state, three new IR absorption peaks were observed in that of $\mathbf{P P}[\mathbf{o x}]_{\text {vac/acid, }}$ i.e., at 1630,1720 , and $3402 \mathrm{~cm}^{-1}$, and these peaks were assigned to the $\mathrm{C}=\mathrm{C}, \mathrm{C}=\mathrm{O}$, and $\mathrm{O}-\mathrm{H}$ stretching vibrations, respectively [45]. The FTIR spectra of PE[ox $]_{\text {vac/acid }}$ and PVC[ox $]_{\text {vac/acid }}$ also suggested the formation of new functional groups (Figures S2c and S3c). The characterization of the nature of the formed unsaturated groups was conducted by solid-state ${ }^{13} \mathrm{C}-\mathrm{NMR}$ and $\mathrm{X}$-ray photoelectron spectroscopy (XPS) studies. The ${ }^{13} \mathrm{C}-\mathrm{NMR}$ spectrum of PP[ox $]_{\text {vac/acid }}$ revealed a peak at $\sim 130 \mathrm{ppm}$, indicating the presence of non-terminal alkene groups. Furthermore, the ${ }^{13} \mathrm{C}$-NMR spectrum showed a peak at $\sim 225 \mathrm{ppm}$, indicating the presence of ketone functionalities in the oxidized polymer. In addition, the high-resolution $\mathrm{C}_{1 \mathrm{~s}}$ and $\mathrm{O}_{1 \mathrm{~s}}$ XPS spectra of PP[ox $]_{\text {vac/acid }}$ indicated the presence of $\mathrm{C}=\mathrm{C}$ (alkenyl, $\left.284.5 \mathrm{eV}\right), \mathrm{C}-\mathrm{C}(\mathrm{alkyl}, 285.1 \mathrm{eV})$, $\mathrm{C}-\mathrm{OH}$ (hydroxyl, 286.3 and $533.6 \mathrm{eV}$ ), and $\mathrm{C}=\mathrm{O}$ (carbonyl, 287.0 and $532.5 \mathrm{eV}$ ) groups (Figure 1f). The ratio between the desaturated $(\mathrm{C}=\mathrm{C})$ and hydroxylated groups $(\mathrm{C}-\mathrm{OH}$ and $\mathrm{C}=\mathrm{O}$ ) in PP[ox $]_{\text {vac/acid }}$ was found to be 1.3:1 (Table S1). Furthermore, Figure 1g,i shows typical scanning electron microscopy (SEM) images of the virgin PP and PP[ox $]_{\text {vac/acid, }}$ respectively. The average size of $\mathbf{P P}[\mathbf{o x}]_{\text {vac/acid }}$ was $\sim 7.5 \mu \mathrm{m}$, whereas that of the virgin PP particle was found to be $\sim 105 \mu \mathrm{m}$. The surface morphology of PP[ox $]_{\text {vac/acid }}$ was highly irregular. Based on energy-dispersive X-ray spectroscopy (EDS) studies, $\mathrm{Cl}$ atoms were found on the surface of PVC[ox $]_{\text {vac/acid, }}$, and chloride anions were also produced during the process. Supplementary Information Figures S2 and S3 show the FTIR spectra, XPS analyses, and SEM images of PE/PE[ox $]_{\text {vac/acid }}$ and PVC/PVC[ox $]_{\text {vac/acid, }}$, respectively.

It is important to note that the production of alkene groups in the polyolefins was enhanced in the presence of acid $\left(\mathrm{KHSO}_{4}\right)$. In comparison with the FTIR spectrum of PP[ox $]_{\text {vac/acid }}$, a smaller C $=C$ stretching peak at $1600 \mathrm{~cm}^{-1}$ was found for PP[ox $]_{\text {vac }}$. From the XPS analyses, the ratio between the unsaturated and hydroxylated entities in PP[ox $]_{\text {vac }}$ was found to be $\sim 0.8: 1$ (Figure 1e,f, Supplementary material (Table S1). In addition, in the presence of acid, the desaturated products of PP, PE, and PVC were obtained in $60 \%$ higher yields than those obtained in the absence of acid (Table S1).

\subsection{Reaction Mechanism}

Scheme 1 shows the proposed activation and oxidation mechanisms for PE, PP, and PVC induced by ball milling with $\mathrm{KMnO}_{4}$. The first step involves the interaction of a $\mathrm{KMnO}_{4}$ molecule and an $\alpha-\mathrm{CH}$ unit in the polymer, followed by the homolytic cleavage of the $\alpha-\mathrm{CH}$ unit via the HAT mechanism, resulting in a $\mathrm{KMn}(\mathrm{VI}) \mathrm{O}_{3}(\mathrm{OH})$ and a $\left[{ }_{\beta} \mathrm{CH}_{2}-\right.$ $\left.{ }_{\alpha} \mathrm{C}^{\bullet}(\mathrm{R})-\right]$ unit. This first HAT is defined as the rate-determining step. Furthermore, we postulated that $\mathrm{KMn}^{\mathrm{VI}} \mathrm{O}_{3}(\mathrm{OH})$ dissociates from the radical species, $\left[{ }_{\beta} \mathrm{CH}_{2-\alpha} \mathrm{C}^{\bullet}(\mathrm{R})-\right]$, leading to a second HAT with a second molecule of $\mathrm{KMnO}_{4}$ via its ${ }_{-} \mathrm{CH}_{2}$ unit, thus forming a di-radical, $\left[-{ }_{\beta} \mathrm{C}^{\bullet} \mathrm{H}-{ }_{\alpha} \mathrm{C}^{\bullet}(\mathrm{R})-\right]$. Finally, the recombination of the two electrons in the di-radical species generates an alkene, $\left[{ }_{\beta} \mathrm{CH}={ }_{\alpha} \mathrm{C}(\mathrm{R})-\right]$, in the polymer chain. The solvent-free, solid-state ball-milling reaction could therefore facilitate the formation of the di-radical and prevent the rebound mechanism [46].

\subsection{DFT Calculations}

To understand the mechanism further, three sets of DFT calculations were performed for the polymers. More specifically, the PE, PP, and PVC polymer chains were modeled using octane, 2,4,6-trimethyloctane, and 3,5-dichlorooctane, respectively. For simplicity, these prototypical molecules were denoted simply as PE, PP, and PVC. The potential energy surface and the structures of the intermediates (INTs) and transition states (TSs) in the oxidation of PP by $\mathrm{KMnO}_{4}$ are shown in Figure 2, whereas those for PE and PP are shown in Schemes S1 and S2, respectively. 

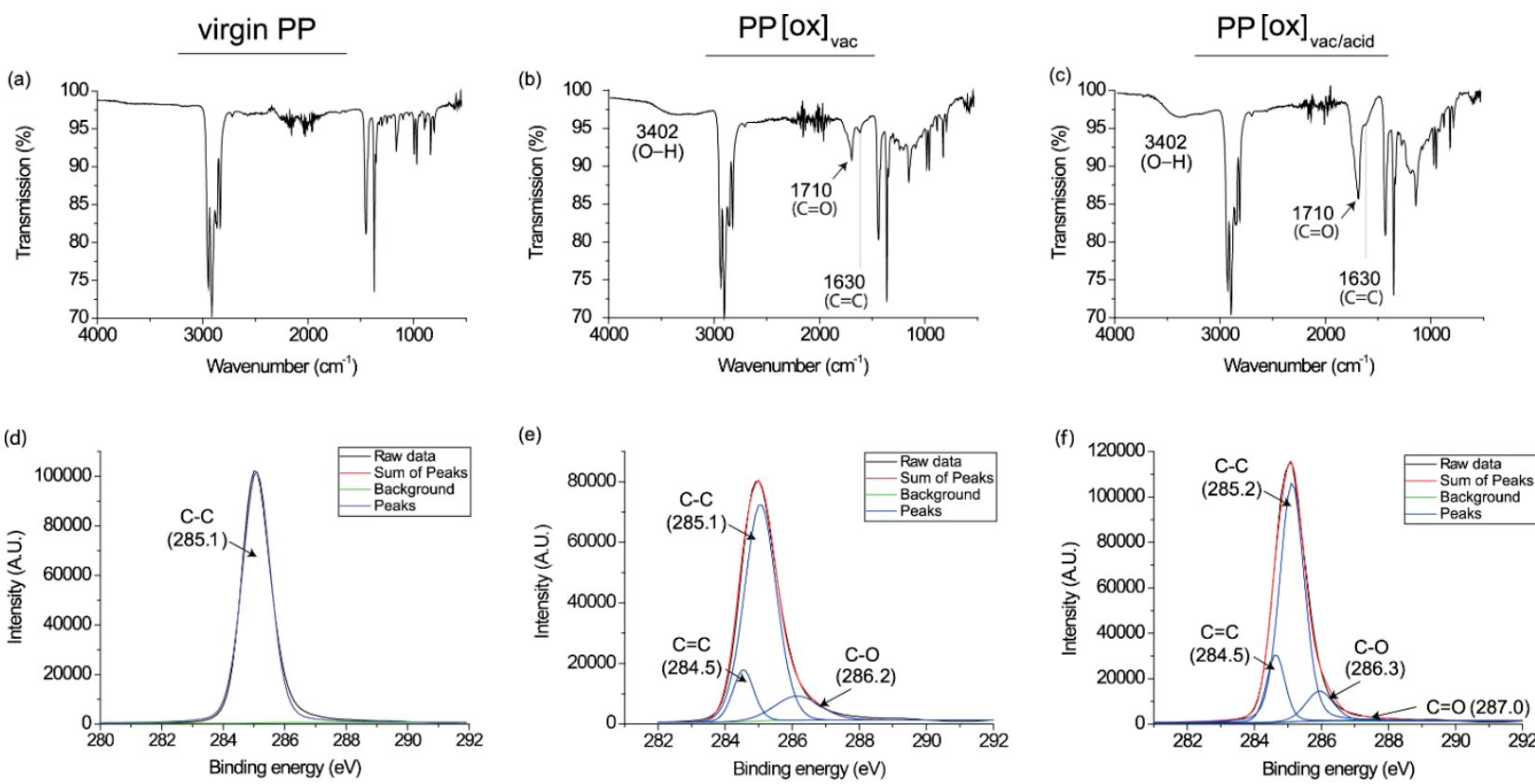

(g)

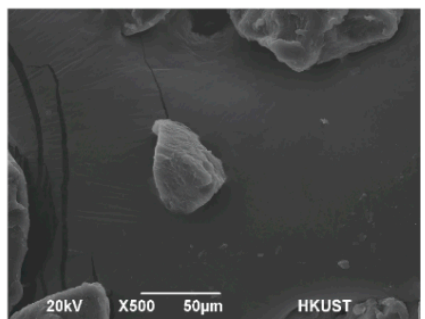

(h)

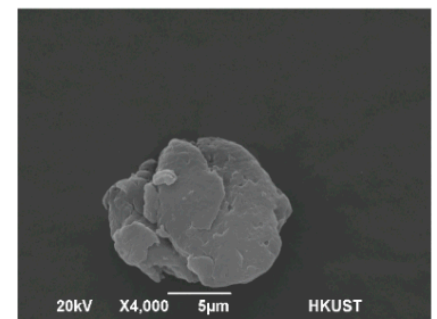

(i)

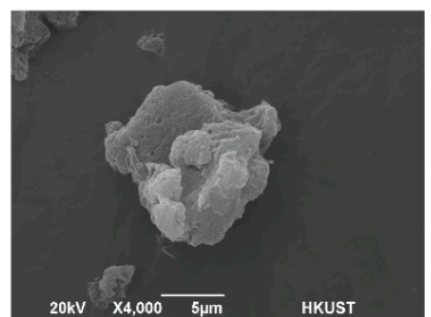

Figure 1. (a-c) FT-IR, (d-f) XPS, (g-i) SEM images of virgin PP, PP[Ox $]_{\text {vac }}$, and PP[Ox $]_{\text {vac/acid }}$.

Before the first step of the reaction, $\mathrm{MnO}_{4}{ }^{-}$forms the van der Waals complex INT1 with a PP chain in an endergonic reaction $\left(\Delta G_{298}=6 \mathrm{kcal} \mathrm{mol}^{-1}\right.$ relative to the energy of the reactants). The reaction then begins when the oxo ligand from the $\mathrm{MnO}_{4}{ }^{-}$ion abstracts an $\mathrm{H}$-atom from the $\alpha$-position of the PP repeating unit, $\left[-{ }_{\beta} \mathrm{CH}_{2}-{ }_{\alpha} \mathrm{CH}\left({ }_{\gamma} \mathrm{CH}_{3}\right)-\right]$, via TS1 $\left(\Delta G^{\ddagger}{ }_{298}=28 \mathrm{kcal} \mathrm{mol}^{-1}\right)$, to form $\left[\left(\mathrm{Mn}^{\mathrm{VI}} \mathrm{O}_{3} \mathrm{OH}\right)\left({ }_{-} \mathrm{CH}_{2}-\alpha \mathrm{C}^{\bullet}\left({ }_{\gamma} \mathrm{CH}_{3}\right)-\right)\right]^{-}$(INT2). The dissociation of INT2 is overall exergonic by $\Delta G_{298}$ of $12 \mathrm{kcal} \mathrm{mol}^{-1}$, yielding a free "PP radical," $\left[\left(-{ }_{\beta} \mathrm{CH}_{2}-\alpha \mathrm{C}^{\bullet}\left({ }_{\gamma} \mathrm{CH}_{3}\right)-\right)\right]$ (rINT), which can be subsequently attacked by another $\mathrm{MnO}_{4}{ }^{-}$ moiety via TS2a. The O-rebound pathway is viable only if INT2 remains; the transfer of its $\mathrm{OH}$ moiety proceeds via TS3 with a high $\Delta G^{\ddagger}{ }_{298}$ of $33 \mathrm{kcal} \mathrm{mol}^{-1}$. Therefore, we suggest that free rINT is formed instead. Consequently, the oxo ligand from another $\mathrm{MnO}_{4}{ }^{-}$ion abstracts an $\mathrm{H}$-atom from the $\beta$-position of rINT to form an alkene, $\left[-{ }_{\beta} \mathrm{CH}={ }_{\alpha} \mathrm{C}(\mathrm{R})-\right]$, within the PP polymer chain via TS2a $\left(\Delta G^{\ddagger} 298=17 \mathrm{kcal} \mathrm{mol}^{-1}\right)$, which is accompanied by a large release of Gibbs free energy ( $\sim 37 \mathrm{kcal} \mathrm{mol}^{-1}$ with respect to rINT). It should be noted that the desaturation of alkanes generally involves a metal-OH intermediate to abstract the second $\mathrm{H}$-atom from an alkane radical [47]. However, according to our calculated energetics, the second $\mathrm{H}$-atom abstraction from the $\beta$-position of the radical site by another metal-oxo is overwhelmingly favorable. We have also investigated alternative pathways, such as the abstraction of a second $\mathrm{H}$-atom from the $\alpha$-position of the neighboring PP repeating unit via TS2b. The $\Delta G^{\ddagger} 298$ (TS2b) is $45 \mathrm{kcal} \mathrm{mol}^{-1}$, which is identical to the $\Delta G^{\ddagger} 298$ (rTS) value for the $\beta, \alpha$-hydrogen atom shift. In other words, following the formation of a radical site, $\mathrm{H}$-atom abstraction at the neighboring carbon atom is greatly facilitated. Thus, the most plausible mechanism for desaturation is successive $\mathrm{H}$-atom abstraction at the $\alpha$ - and $\beta$-positions within the same repeating unit of PP. The potential energy surfaces (Schemes S1 and S2) for the desaturation reactions of PE and PVC also 
support this conclusion, despite some minor differences in the energetics arising from the different substituents.
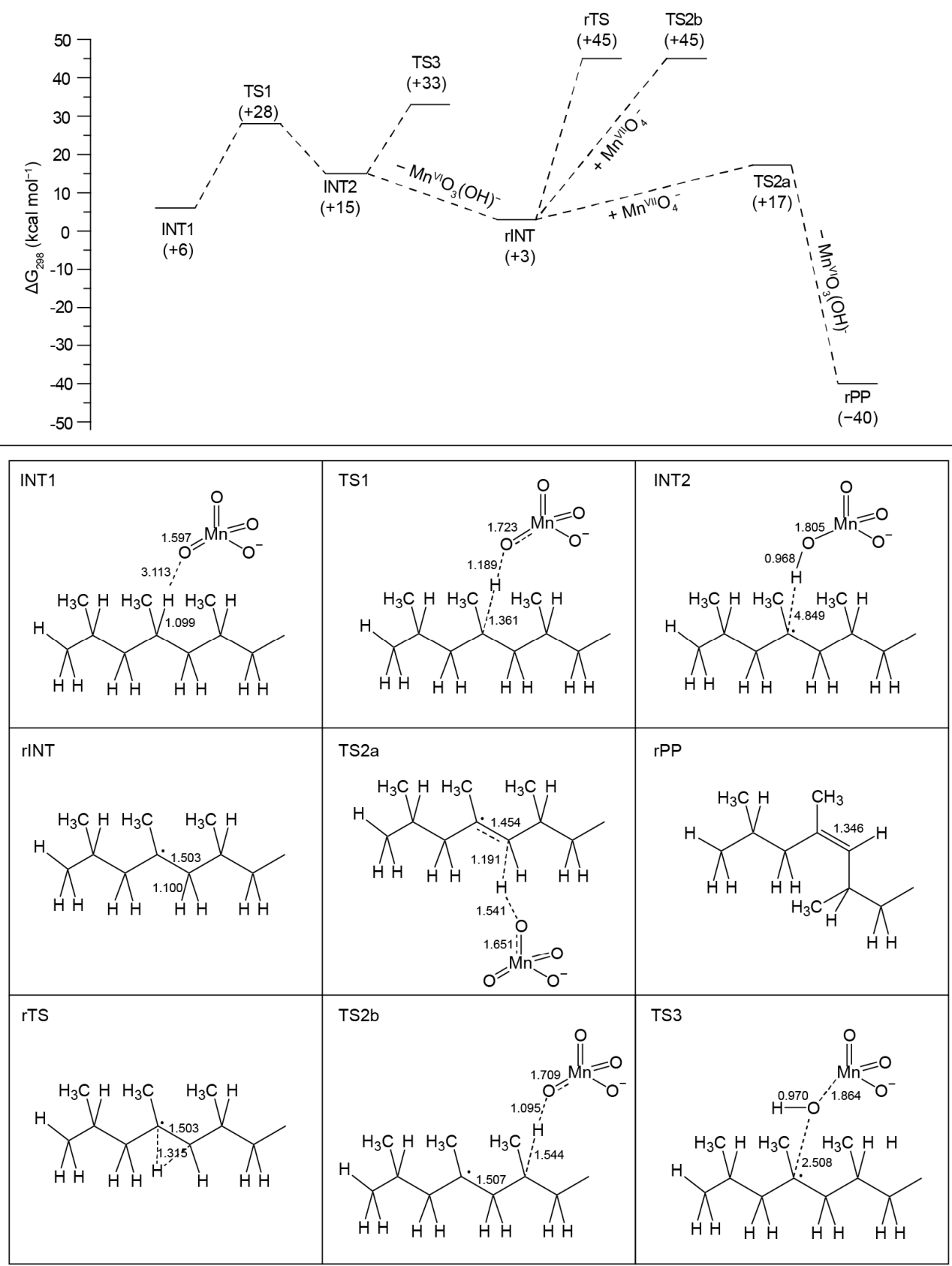

Figure 2. (Top) Potential energy surface for the oxidation of PP by $\mathrm{MnO}_{4}{ }^{-}$at the B3LYP/LanL2DZ level of theory for Mn and the B3LYP/6-31++G(d,p) level of theory for non-metal atoms. All energies are in $\mathrm{kcal} / \mathrm{mol}$ and relative to those of the free reactants. (Bottom) Structures of intermediates (INTs) and transition states (TSs); the unit of bond distance is $\AA$.

\section{Conclusions}

This study demonstrated an effective mechanochemical method to activate inert PE, PP, and PVC through a solid-state reaction by ball milling with potassium permanganate. Our results indicated that the formation of alkene units in the polymer chain was evidence for a desaturation mechanism. Oxidation of the polymer by a sufficient amount of $\mathrm{KMnO}_{4}$ led to polymer breakdown and the formation of gaseous fuels such as methane, carbon monoxide, and hydrogen. Although at this moment it is not economically viable to use a quantitative amount of permanganate to generate coal gas from plastic waste (despite the 
fact that the produced $\mathrm{Mn}$ (II) oxide can be recycled back to $\mathrm{KMnO}_{4}$ for further oxidation), our system provides insights for the further development of metal-oxo catalytic systems for the large-scale oxidation of solid plastic waste, which may have a positive impact on environmental chemistry and petrochemistry.

Supplementary Materials: The following are available online at https:/ /www.mdpi.com/article/10 .3390/polym13213672/s1, Figure S1: GC-TCD chromatograms of the gaseous products generated from the mechanochemical solid-state reaction of virgin PE $(0.50 \mathrm{~g}, 18 \mathrm{mmol}), \operatorname{PP}(0.50 \mathrm{~g}, 12 \mathrm{mmol})$, or PVC (0.50 g, $8 \mathrm{mmol})$ with $\mathrm{KMnO}_{4}(1.2$ molar equivalents: $21.6 \mathrm{mmol}$ for PE; $14.4 \mathrm{mmol}$ for PP; and $9.6 \mathrm{mmol}$ for PVC) at a ball milling speed of $800 \mathrm{rpm}$ for $12 \mathrm{~h}$ under vacuum conditions showing peaks for (i) hydrogen, (ii) nitrogen, (iii) oxygen, (iv) methane, and (v) carbon monoxide, Figure S2: $(\mathrm{a}-\mathrm{c})$ FTIR characterization, (d-f) XPS analysis, and (g-i) SEM images of virgin PE, PE[Ox] $]_{\text {vac }}$, and PE[Ox $]_{\text {vac/acid }}$, Figure S3: (a-c) FTIR characterization, $(\mathrm{d}-\mathrm{f})$ XPS analysis, and $(\mathrm{g}-\mathrm{i})$ SEM images of

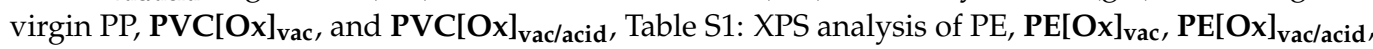
PP, PP[Ox $]_{\text {vac }}$, PP $[\mathbf{O x}]_{\text {vac/acid }}$, PVC, PVC[Ox $]_{\text {vac }}$, PVC $[0 x]_{\text {vac/acid }}$, Scheme S1: (Top) Potential energy surface for the oxidation of PE by $\mathrm{MnO}_{4}{ }^{-}$at the B3LYP/LanL2DZ level of theory for Mn and the $\mathrm{B} 3 \mathrm{LYP} / 6-31++\mathrm{G}(\mathrm{d}, \mathrm{p})$ level of theory for non-metal atoms. All energies are in $\mathrm{kcal} / \mathrm{mol}$ and relative to those of the free reactants. (Bottom) Structures of intermediates (INTs) and transition states (TSs); the unit of bond distance is $\AA$, Scheme S2: (Top) Potential energy surface for the oxidation of PVC by $\mathrm{MnO}_{4}{ }^{-}$at the B3LYP/LanL2DZ level of theory for Mn and the B3LYP/6-31++G(d,p) level of theory for non-metal atoms. All energies are in $\mathrm{kcal} / \mathrm{mol}$ and relative to those of the free reactants. (Bottom) Structures of intermediates (INTs) and transition states (TSs); the unit of bond distance is $\AA$, Video S1: Burning the gases collected from ball milling of real plastic waste (HDPE washing bottle, $18.0 \mathrm{mmol}$ ) with $\mathrm{KMnO}_{4}(21.6 \mathrm{mmol})$ under vacuum at $25^{\circ} \mathrm{C}$ for $48 \mathrm{~h}$.

Author Contributions: C.-F.C. and K.-C.L. are the co-authors of this manuscript. C.-F.C. designed the study, wrote the article, and made the final approval of the version to be submitted. C.-F.C. performed the experiments and the analyses, C.-B.G. conducted the material characterization. C.-S.L. and K.-C.L. performed the DFT calculations. All authors have read and agreed to the published version of the manuscript.

Funding: This research was funded by (i) the Dean's Research Fund of the Faculty of Liberal Arts and Social Sciences and (ii) the Department of Science and Environmental Studies at The Education University of Hong Kong, Hong Kong Special Administrative Region, China (Project Nos. 04300, R4072, 04417, and 04489) and The APC was funded by the Department of Science and Environmental Studies at The Education University of Hong Kong.

Institutional Review Board Statement: Not applicable.

Informed Consent Statement: Not applicable.

Data Availability Statement: The data that support the findings of this study are available from the corresponding author, upon reasonable request.

Acknowledgments: We acknowledge The Hong Kong Polytechnic University for carrying out the solid-state NMR studies. We also thank The Hong Kong University of Science and Technology for carrying out the SEM and XPS analyses.

Conflicts of Interest: The authors declare no conflict of interest.

\section{References}

1. Plastics Europe. Plastics-The Facts 2020. Available online: https://www.plasticseurope.org/application/files/5716/0752/4286 /AF_Plastics_the_facts-WEB-2020-ING_FINAL.pdf (accessed on 20 October 2021).

2. EPA. Advancing Sustainable Materials Management 2018 Fact Sheet. Available online: https://www.epa.gov/sites/default/ files/2021-01/documents/2018_ff_fact_sheet_dec_2020_fnl_508.pdf (accessed on 20 October 2021).

3. Andrady, A.L. Wavelength sensitivity in polymer photodegradation. In Polymer Analysis Polymer Physics; Springer: Berlin/Heidelberg, Germany, 1997; pp. 47-94.

4. Sharuddin, S.D.A.; Abnisa, F.; Daud, W.M.A.W.; Aroua, M.K. A review on pyrolysis of plastic wastes. Energy Convers. Manag. 2016, 115, 308-326. [CrossRef]

5. Chakraborty, J.; Sarkar, J.; Kumar, R.; Madras, G. Ultrasonic degradation of polybutadiene and isotactic polypropylene. Polym. Degrad. Stabil. 2004, 85, 555-558. [CrossRef] 
6. Arutchelvi, J.; Sudhakar, M.; Arkatkar, A.; Doble, M.; Bhaduri, S.; Uppara, P.V. Biodegradation of polyethylene and polypropylene. Indian J. Biotechnol. 2008, 7, 9-22.

7. Ragaert, K.; Delva, L.; Van Geem, K. Mechanical and chemical recycling of solid plastic waste. Waste Manag. 2017, 69, 24-58. [CrossRef]

8. Walzak, M.J.; Flynn, S.; Foerch, R.; Hill, J.M.; Karbashewski, E.; Lin, A.; Strobel, M. UV and ozone treatment of polypropylene and poly(ethylene terephthalate). J. Adhes. Sci. Technol. 1995, 9, 1229-1248. [CrossRef]

9. Hwang, E.-Y.; Choi, J.-K.; Kim, D.-H.; Park, D.-W.; Woo, H.-C. Catalytic degradation of polypropylene I. Screening of catalysts. Korean J. Chem. Eng. 1998, 15, 434-438. [CrossRef]

10. Oprea, C.V. Mechanochemical degradation of polymers. Polym. Mech. 1978, 14, 783-792. [CrossRef]

11. McNaught, A.D. Compendium of Chemical Terminology; Blackwell Science Oxford: Oxford, UK, 1997; Volume 1669.

12. Boldyrev, V.V.; Tkáčová, K. Mechanochemistry of Solids: Past, Present, and Prospects. J. Mater. Synth. Process. 2000, 8, 121-132. [CrossRef]

13. Užarević, K.; Halasz, I.; Đilović, I.; Bregović, N.; Rubčić, M.; Matković-Čalogović, D.; Tomišić, V. Dynamic Molecular Recognition in Solid State for Separating Mixtures of Isomeric Dicarboxylic Acids. Angew. Chem. Int. Ed. 2013, 52, 5504-5508. [CrossRef]

14. Jeon, I.-Y.; Shin, Y.-R.; Sohn, G.-J.; Choi, H.-J.; Bae, S.-Y.; Mahmood, J.; Jung, S.-M.; Seo, J.-M.; Kim, M.-J.; Chang, D.W.; et al. Edge-carboxylated graphene nanosheets via ball milling. Proc. Natl. Acad. Sci. USA 2012, 109, 5588-5593. [CrossRef]

15. Ranu, B.C.; Chatterjee, T.; Mukherjee, N. CHAPTER 1 Carbon-Heteroatom Bond Forming Reactions and Heterocycle Synthesis under Ball Milling. In Ball Milling Towards Green Synthesis: Applications, Projects, Challenges; The Royal Society of Chemistry: London, UK, 2015; pp. 1-33.

16. Szuppa, T.; Stolle, A.; Ondruschka, B.; Hopfe, W. Solvent-free dehydrogenation of [gamma]-terpinene in a ball mill: Investigation of reaction parameters. Green Chem. 2010, 12, 1288-1294. [CrossRef]

17. Naimi-Jamal, M.R.; Mokhtari, J.; Dekamin, M.G.; Kaupp, G. Sodium Tetraalkoxyborates: Intermediates for the Quantitative Reduction of Aldehydes and Ketones to Alcohols through Ball Milling with $\mathrm{NaBH}_{4}$. Eur. J. Org. Chem. 2009, 21, 3567-3572. [CrossRef]

18. Su, W.; Yu, J.; Li, Z.; Jiang, Z. Solvent-Free Cross-Dehydrogenative Coupling Reactions under High-Speed Ball-Milling Conditions Applied to the Synthesis of Functionalized Tetrahydroisoquinolines. J. Org. Chem. 2011, 76, 9144-9150. [CrossRef]

19. Ralphs, K.; Hardacre, C.; James, S.L. Application of heterogeneous catalysts prepared by mechanochemical synthesis. Chem. Soc. Rev. 2013, 42, 7701-7718. [CrossRef]

20. Balaz, P.; Achimovicova, M.; Balaz, M.; Billik, P.; Cherkezova-Zheleva, Z.; Criado, J.M.; Delogu, F.; Dutkova, E.; Gaffet, E.; Gotor, F.J.; et al. Hallmarks of mechanochemistry: From nanoparticles to technology. Chem. Soc. Rev. 2013, 42, 7571-7637. [CrossRef]

21. Wang, G.-W. Mechanochemical organic synthesis. Chem. Soc. Rev. 2013, 42, 7668-7700. [CrossRef]

22. Friscic, T. Supramolecular concepts and new techniques in mechanochemistry: Cocrystals, cages, rotaxanes, open metal-organic frameworks. Chem. Soc. Rev. 2012, 41, 3493-3510. [CrossRef]

23. Sepelak, V.; Duvel, A.; Wilkening, M.; Becker, K.-D.; Heitjans, P. Mechanochemical reactions and syntheses of oxides. Chem. Soc. Rev. 2013, 42, 7507-7520. [CrossRef]

24. Hick, S.M.; Griebel, C.; Restrepo, D.T.; Truitt, J.H.; Buker, E.J.; Bylda, C.; Blair, R.G. Mechanocatalysis for biomass-derived chemicals and fuels. Green Chem. 2010, 12, 468-474. [CrossRef]

25. Delori, A.; Friscic, T.; Jones, W. The role of mechanochemistry and supramolecular design in the development of pharmaceutical materials. CrystEngComm 2012, 14, 2350-2362. [CrossRef]

26. Burmeister, C.F.; Kwade, A. Process engineering with planetary ball mills. Chem. Soc. Rev. 2013, 42, 7660-7667. [CrossRef] [PubMed]

27. Guo, X.; Xiang, D.; Duan, G.; Mou, P. A review of mechanochemistry applications in waste management. Waste Manag. 2010, 30, 4-10. [CrossRef]

28. Baranwal, K. Mechanochemical degradation of an EPDM polymer. J. Appl. Polym. Sci. 1968, 12, 1459-1469. [CrossRef]

29. Cavalieri, F.; Padella, F. Development of composite materials by mechanochemical treatment of post-consumer plastic waste. Waste Manag. 2002, 22, 913-916. [CrossRef]

30. Inoue, T.; Miyazaki, M.; Kamitani, M.; Kano, J.; Saito, F. Mechanochemical dechlorination of polyvinyl chloride by co-grinding with various metal oxides. Adv. Powder Technol. 2004, 15, 215-225. [CrossRef]

31. Inoue, T.; Miyazaki, M.; Kamitani, M.; Kano, J.; Saito, F. Dechlorination of polyvinyl chloride by its grinding with KOH and NaOH. Adv. Powder Technol. 2005, 16, 27-34. [CrossRef]

32. Tongamp, W.; Zhang, Q.; Saito, F. Mechanochemical decomposition of PVC by using $\mathrm{La}_{2} \mathrm{O}_{3}$ as additive. J. Hazard. Mater. 2006, 137, 1226-1230. [CrossRef] [PubMed]

33. Tongamp, W.; Zhang, Q.; Saito, F. Hydrogen generation from polyethylene by milling and heating with $\mathrm{Ca}(\mathrm{OH})^{2}$ and $\mathrm{Ni}(\mathrm{OH})^{2}$. Int. J. Hydrog. Energy 2008, 33, 4097-4103. [CrossRef]

34. Tongamp, W.; Zhang, Q.; Saito, F. Generation of $\mathrm{H}_{2}$ gas from polystyrene and poly(vinyl alcohol) by milling and heating with $\mathrm{Ni}(\mathrm{OH})_{2}$ and $\mathrm{Ca}(\mathrm{OH})_{2}$. Fuel Process. Technol. 2010, 91, 272-276. [CrossRef]

35. Tongamp, W.; Zhang, Q.; Shoko, M.; Saito, F. Generation of hydrogen from polyvinyl chloride by milling and heating with CaO and $\mathrm{Ni}(\mathrm{OH})_{2}$. J. Hazard. Mater. 2009, 167, 1002-1006. [CrossRef] 
36. Vollmer, I.; Jenks, M.J.F.; Roelands, M.C.P.; White, R.J.; van Harmelen, T.; de Wild, P.; van der Laan, G.P.; Meirer, F.; Keurentjes, J.T.F.; Weckhuysen, B.M. Beyond mechanical recycling: Giving new life to plastic waste. Angew. Chem. Int. Ed. 2020, $59,15402$. [CrossRef] [PubMed]

37. Huang, L.; Wang, H.; Wang, C.; Zhao, J.; Zhang, B. Microwave-assisted surface modification for the separation of polycarbonate from polymethylmethacrylate and polyvinyl chloride waste plastics by flotation. Waste Manag. Res. 2017, 35, 294. [CrossRef]

38. Becke, D. Density-functional thermochemistry. V. Systematic optimization of exchange-correlation functionals. J. Chem. Phys. 1997, 107, 8554. [CrossRef]

39. Becke, D. A new mixing of Hartree-Fock and local density-functional theories. J. Chem. Phys. 1993, 98, 1372. [CrossRef]

40. Becke, D. Density-functional thermochemistry. III. The role of exact exchange. J. Chem. Phys. 1993, 98, 5648. [CrossRef]

41. Hay, P.J.; Wadt, W.R. Ab initio effective core potentials for molecular calculations. Potentials for K to Au including the outermost core orbitals. J. Chem. Phys. 1985, 82, 299. [CrossRef]

42. Singh, N.; Lee, D.G. Permanganate: A green and versatile industrial oxidant. Org. Process Res. Dev. 2001, 5, 599. [CrossRef]

43. Gong, J.; Chen, X.; Tang, T. Recent progress in controlled carbonization of (waste) polymers. Prog. Polym. Sci. 2019, 94, 1. [CrossRef]

44. Song, R.; Jiang, Z.; Bi, W.; Cheng, W.; Lu, J.; Huang, B.; Tang, T. The combined catalytic action of solid acids with nickel for the transformation of polypropylene into carbon nanotubes by pyrolysis. Eur. Chem. J. 2007, 13, 3234. [CrossRef]

45. Chow, C.F.; Chan, C.S. A Study on Fenton Technology for Polypropylene Waste Degradation and Recovery of High-Value Chemicals. In Environmental Sustainability and Education for Waste Management; So, W.M.W., Chow, C.F., Lee, J.C.K., Eds.; Springer Nature: Singapore, 2019; pp. 169-180.

46. Wolfe, S.; Ingold, C.F.; Lemieux, R.U. Oxidation of olefins by potassium permanganate. Mechanism of alpha-ketol formation. J. Am. Chem. Soc. 1981, 103, 938. [CrossRef]

47. Hull, J.F.; Balcells, D.; Sauer, E.L.O.; Raynaud, C.; Brudvig, G.W.; Crabtree, R.H.; Eisenstein, O. Manganese catalysts for C-H activation: An experimental/theoretical study identifies the stereoelectronic factor that controls the switch between hydroxylation and desaturation pathways. J. Am. Chem. Soc. 2010, 132, 7605. [CrossRef] [PubMed] 